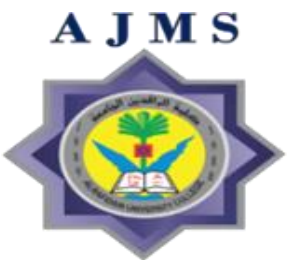

Online ISSN (2789-3219)

\title{
Toxic Effects of Platinum Compounds: Molecular Mechanisms of Toxicity
}

\author{
Mayyadah Mahmood Ali ${ }^{1}$, Tavga Ahmad Aziz ${ }^{2 *}$ \\ ${ }^{1}$ Department of Pharmacy, Hiwa Hospital, Sulaimani Directorate of Health, Kurdistan Region, Iraq \\ ${ }^{2}$ Department of Pharmacology and Toxicology, College of Pharmacy, University of Sulaimani, Kurdistan Region, Iraq
}

Received: 14 Sep 2021; Revised: 15 Oct 2021; Accepted: 24 Oct 2021

\begin{abstract}
Despite their effectiveness as a crucial component of combination chemotherapy against solid tumors, platinum compounds have many serious side effects that limit their use. This review article focuses on the various toxic effects of platinum compounds in cancer patients and the mechanisms of associated toxicity. It also describes the future directions for developing novel platinum-based compounds using both animal and human studies. A list of publications was included after searching the Google and Google Scholar databases, PubMed, and scientific journals between 2005-2020. Platinum-based medicines, as soft nucleophiles, can freely bind to proteins containing thiol groups like glutathione and DNA in normal and malignant cells, particularly those in fast-growing tissues, causing a variety of dangerous side effects. Fast-growing tissues such as the mucous membranes of the mouth, throat, stomach, and intestines, bone marrow, and hair follicles can be damaged by cytotoxic chemotherapy, resulting in gastrointestinal toxicities, myelosuppression, and hair loss. Platinum compounds also cause nephrotoxicity and hepatotoxicity, which are well-known side effects. Current platinum-based chemotherapy treatments have been restricted in the last decade, prompting a search for novel platinum-based medications with mechanisms of action distinct from those of existing chemotherapeutics.
\end{abstract}

Keywords: Platinum drugs, Neurotoxicity, Nephrotoxicity, Ototoxicity, Mechanisms

$$
\text { الاثار الجاتبيه السامه للمركبات البلاتينيه: الآليه الجزيئيه للتسمم }
$$

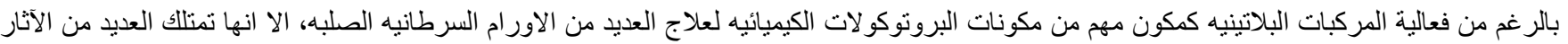

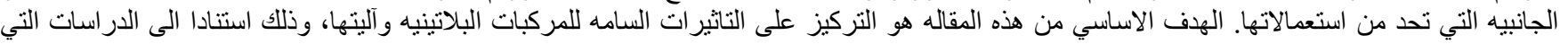

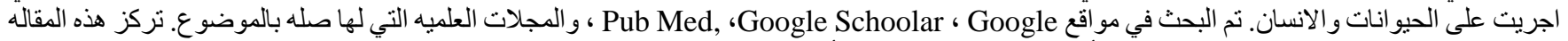

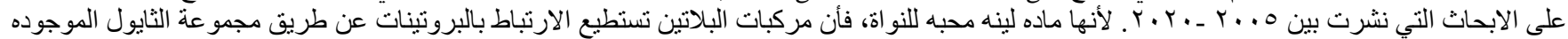

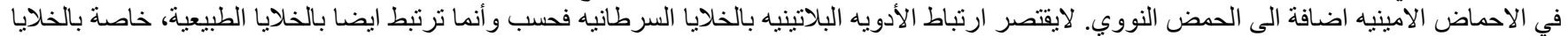

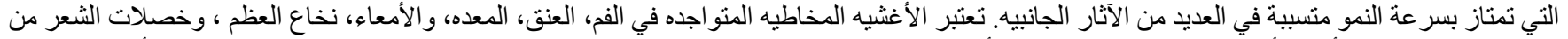

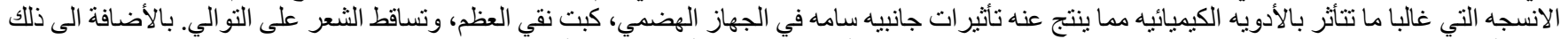

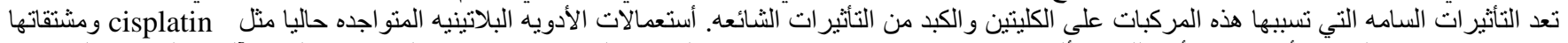

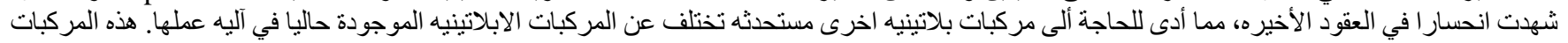

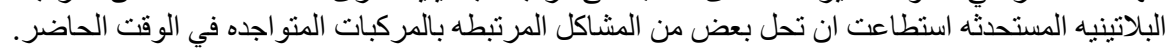

*Corresponding author: Tavga A. Aziz, Department of Pharmacology and Toxicology, College of Pharmacy, University of Sulaimani, Kurdistan Region, Iraq; Email: tavga.aziz@univsul.edu.iq

Article citation: Ali MM, Aziz TA. Toxic effects of platinum compounds: Molecular mechanisms of Toxicity. Al-Rafidain J Med Sci. 2021;1:81-88. doi: 10.54133/ajms.vli.32. 


\section{INTRODUCTION}

Platinum (Pt) drugs are one of the most effective cytotoxic agents accessible to oncologists. Although they include a wide range of compounds, cisplatin and the newer derivatives such as carboplatin and oxaliplatin are the most widely used [1]. Heptaplatin (Korea), Lobaplatin (China), Miriplatin (Japan), and Nedaplatin (USA) are four platinum-based drugs that have received regulatory approval in their respective countries [2]. Despite their effectiveness as critical components of combination chemotherapy regimens against a wide range of solid tumors (lung, testes, ovary, cervix uteri, head and neck, colon, and rectum), platinum compounds have a variety of significant adverse effects that restrict their use [3]. Following intravenous administration, platinum drugs usually bind to serum proteins, especially human serum albumin [2]. They penetrate cells using various methods; the most notable are copper transporters, specifically highaffinity copper transporter-1 [4]. Inside the cells, the drug is equated, and its labile groups are lost due to the low salt concentration (chlorides or carboxylate-based ligands). Then, it becomes highly reactive; therefore, it can bind to a wide range of intracellular biomolecules [5]. As a soft nucleophile, platinum-based drugs can freely bind to peptides and proteins with sulfur residues of thiolcontaining amino acids such as cysteine, methionine, and, in particular, with the antioxidant peptide glutathione. However, platinum compounds' principal target is nuclear DNA [5]. They bind primarily to the N7 position of guanine, but they also bind to adenosine residues, causing DNA to unwind and twist [5]. As a result, apoptosis is triggered when DNA transcription and replication are disrupted [6]. This binding is not restricted to cancerous cells but also to normal cells, especially those of fastgrowing tissues. Due to their poor selectivity, platinumbased drugs, like other cytotoxic drugs, have many serious adverse effects [7]. The mucous membranes of the mouth, neck, intestines, and stomach are among the fast-growing tissues affected by cytotoxic agents, resulting in gastrointestinal toxicities. These drugs affect bone marrow and hair, leading to myelosuppression and loss of hair, respectively. Hair loss or alopecia occurs in eyebrows, facial and body hair, and hair follicles of the ear, resulting in ototoxicity. Nephrotoxicity and hepatotoxicity are wellknown side effects of platinum-based compounds. Kidney damage occurs due to drug excretion in the urine, and liver toxicity occurs due to the body's attempt to metabolize the drug in the liver, allowing exposure of both organs to the drug [7]. It has been found that there is a clear relationship between Platinum-based drugs' toxicity and their degree of reactivity determined by the lability of their leaving groups. The more labile the group(s), the more reactive the complex is and the more side effects it causes [7]. For each drug, there is a different dose-limiting toxicity (DLT), characterized as a medication side effect that is severe enough to prohibit the drug dose or level of treatment from being increased. For example, nephrotoxicity, myelosuppression, and neurotoxicity are DLTs of cisplatin, carboplatin, and oxaliplatin, respectively [7]. This review article will primarily focus on the various toxic effects of platinum-based compounds on cancer patients and the mechanisms of toxicity associated with each toxicity by including animal and human studies as well as some future directions for developing alternative novel platinum compounds. It primarily focuses on trials conducted between the years 2005 and 2020.

\section{METHODS}

We performed a precise article review that focuses on the toxic effects of platinum-based compounds and their mechanism of toxicity. We searched the Google and Google scholar databases, PubMed, and scientific journals. A reference list of relevant articles was included. Many keywords were used, including platinum-based compounds, Platinum toxicity, neurotoxicity of platinumbased compounds, assessment of platinum-induced neurotoxicity, cardiotoxicity of platinum-based compounds, platinum nephrotoxicity, hematological adverse effects of platinum-based drugs, and novel platinum-based compounds. The search was limited to the period from 2010 to 2020 and from many articles and studies. Twenty review articles and 45 original articles were selected for further analysis, depending on the inclusion and exclusion criteria of the review article. Original articles, animal studies, excremental studies, and clinical trials were included.

\section{Determining the intensity of a platinum-based drug's adverse effects}

The scale developed by the National Cancer Institute (NCI) of the United States, which is known as the Common Terminology Criteria for Adverse Events scale, is widely used for scoring the intensity of adverse reactions of platinum-based drugs as follow: Grade 1 is described as mild in Version 4 of the guidelines, and it refers to asymptomatic or mild symptoms for which intervention is not required. Grade 2: When limited, local, or non-invasive intervention is required, or when side effects restrict ageappropriate functional daily activity, it is classified as moderate. Grade 3: These are medically relevant side effects that are not instantly life-threatening but require acute or prolonged hospitalization and are classified as severe, or Grade 3. Grade 4 refers to a life-threatening side effect that necessitates immediate medical attention. Grade 5 refers to death as an outcome of the side effects [8]. 


\section{RESULTS AND DISCUSSION}

Different side effects are associated with the three platinum products, which can be divided into seven categories as follows:

\section{NEUROTOXICITY}

Neurotoxicity is a common side effect of cisplatin. It frequently occurs during the use of oxaliplatin. About 60 to $95 \%$ of patients who receive oxaliplatin develop neurotoxicity. The incidence of chronic peripheral sensory neuropathy (PSN) increases when patients are administered cumulative doses of cisplatin or oxaliplatin that exceed $500 \mathrm{mg} / \mathrm{m}^{2}$ and $750 \mathrm{mg} / \mathrm{m}^{2}$, respectively [9]. Many different mechanisms are suggested for the Pt-based chemotherapy-induced peripheral neuropathy (CIPN), which includes the following:

\section{Nuclear DNA damage}

Both DNA adducts (DNA-protein cross-links and intrastrand and inter-strand DNA) are formed upon binding of PT compounds with DNA. They inhibit DNA base excision repair and transcription $[10,11]$. These alterations in cell functions are critical for the therapeutic efficacy of Pt-based drugs. However, they also harm non-mitotic cells like dorsal root ganglion (DRG) neurons, which require a high metabolism as well as a high level of protein and organelle production to maintain long axons. They preferentially accumulated in DRG neurons due to the presence of a fenestrated capillary network. In addition to the lack of a blood-brain barrier that allowed easy access to sensory neurons [12]. As a result, DRG-induced DNA damage causes neuronal shrinkage in sensory neurons, which is the most critical step in neurotoxicity development [11]. Copper transporter-1 (CTR1) and organic cation transporter-2 are two separate forms of neuronal membrane transporters that aid in the uptake of Pt-based medicines into DRG neurons (OCT2). Therefore, upregulation of these transporters inside neurons leads to the progression or advancement of neurotoxicity [13]. A link between DNA adduct levels and the severity of neurotoxicity has been discovered. An in vitro study showed that the amounts of Platinum-DNA adducts created by cisplatin were three times higher than those formed by equimolar oxaliplatin doses and killed considerably more neuronal cells than oxaliplatin [14]. Platinum-induced DNA damage also causes apoptosis and neuron loss in DRG neurons, according to several in-vivo and in-vitro preclinical studies. Cisplatin causes p53 activation, bax translocation, mitochondrial cytochrome c release, and caspase- 3 and caspase- 9 activation in neural cells. Among other things, DRG neurons attempt to reenter the cell cycle again from the G0 phase after being exposed to cisplatin; this event can be a source of neuronal damage $[15,16]$.

\section{Mitochondrial DNA damage}

It was proven that cisplatin binds to mitochondrial DNA with the same affinity as nuclear DNA. It produces suppression of the transcriptional activity of the mitochondrial DNA, induction of morphological alterations in the mitochondrial DNA, triggering electron transport chain destruction, decreasing adenosine triphosphate (ATP) production, energy loss, as well as a rise in reactive oxygen species production [17]. Consequently, these events will perturb mitochondrial permeability transfer pores, depolarization of the mitochondrial membrane, calcium accumulation inside the cell, and apoptotic protein expression [17]. Cisplatin affects mitochondrial fusion and fission protein expression, which govern the structure, the size, and the number of mitochondria [18]. Based on results obtained from cisplatin-treated mice's DRG and tibial nerves, Bobylev et al. discovered mitochondrial swelling and death due to a substantial drop in mitofusin-2 expression levels in mitochondrial fusion protein [18]. Furthermore, other studies have proved that cisplatin affects the apoptotic mitochondrial pathway via cystine c-release and caspase activation. In particular, they discovered a substantial increase in caspase-3 levels, an apoptotic marker, in cultures of DRG neurons incubated with cisplatin compared to the untreated cultures using an immunoblotting technique [15]. Cullen and colleagues hypothesized in 2007 that mitochondrial permeability transition pore (mPTP) modification could boost cystine crelease, specifically through interactions between PT adducts and VDAC (a structural element of mPTP) [19]. Recently, it has been reported that oxaliplatin forms fewer DNA adducts than cisplatin. It maintains cytotoxicity via inducing immunogenic cell death. Based on recent reports, it promotes $\mathrm{T}$ cell-dependent immune responses and disrupts ribosome biogenesis [20].

\section{Oxidative stress}

Reduced antioxidant defenses and homeostatic failure can cause oxidative stress and lead to neurodegeneration [17]. Because of their high phospholipid content and inadequate cellular antioxidant defenses, mammalian nerves with long axons are particularly sensitive to ROS. Furthermore, the axoplasm is densely packed with mitochondria, and multiple investigations have suggested that axonal cytotoxicity contributes to CIPN [21]. 


\section{Voltage-gated ion channel dysfunction}

The dysfunction of sodium and potassium channels as well as transient receptor potential channels (TRP channels) was found to be associated with the development of CIPN. Platinum-based compounds significantly delay the inactivation of sensory neurons and reduce the peak $\mathrm{Na}^{+}$ current, resulting in a longer relative refractory time. The metabolite oxalate (diaminocyclohexane-platinum-C2O4) of oxaliplatin can also affect $\mathrm{Na}^{+}$channels indirectly by chelating extracellular calcium ions. As a result, sensory neurons become hyperexcitable, leading to spontaneous ectopic discharges [22]. Oxaliplatin's effect on voltagegated $\mathrm{Na}^{+}$channels is unique, resulting in cold-aggravated peripheral neuropathic pain [23]. Oxaliplatin was also discovered to induce action potential broadening and repeated firing, implying an inhibitory action on neuronal fast and slow potassium channels. Sittl et al. found that Flupirtine can minimize oxaliplatin-triggered peripheral nerve hyperexcitability by increasing axonal potassium conductance [24]. Unlike oxaliplatin, cisplatin does not have a significant effect on neuronal sodium or potassium channel activity. In an experimental animal study, treatment with cisplatin increases the flux of calcium ions in rats' DRG neurons. The upregulation of N-type calcium channels was the primary cause of increased intracellular calcium levels as well as induced Caspases-3 and apoptosis activity [25].

\section{Neuro inflammation}

Neuroinflammation is a process characterized by immune cell infiltration and activation as well as the production of cytokines and chemokines by peripheral and central glial cells. It is considered a key mechanism leading to CIPN complexity. The relationship between oxaliplatin-induced neuropathic pain and glial activation was proposed by Mannelli et al, who discovered a temporary stimulation of the spinal cord, microglia and astrocytes, and supraspinal areas associated with pain regulation, as well as a decrease in mechanical and thermal pain thresholds, in a rat model of oxaliplatin-induced peripheral neuropathy [26]. It has also been found that CIPN is linked to an increase in proinflammatory cytokines (tumor necrosis factor, interleukin (IL)-1, and IL-6) and a reduction in anti-inflammatory cytokines in the DRG and spinal cord [27].

\section{Dysregulation of intracellular signaling and receptor downregulation}

Via a variety of intracellular signaling pathways, PT causes uncontrolled proteolysis. Intracellular $\mathrm{Ca}^{2+}$ plays a significant role in cellular homeostasis as a second messenger, and its disruption is also linked to CIPN. It has been found that $\mathrm{Ca}^{2+}$ concentration fluctuations can affect membrane excitability, neurotransmitter release, and gene expression [28]. Activation of other second messenger signaling molecules, like protein kinases and caspases, may also cause axonal degeneration [29]. In rats, the alpha7-nicotinic acetylcholine receptor (nAChR) was suppressed in the sciatic nerve, DRG, and the spinal cord after treatment with $2.4 \mathrm{mg} / \mathrm{kg} /$ day intraperitoneal oxaliplatin for a 3-week duration [30].

\section{NEPHROTOXICITY}

Nephrotoxicity is a broad concept that encompasses numerous distinct side effects related to the kidneys' main functions of filtration, reabsorption, and excretion. Therefore, monitoring is needed before and after treatment with each of the three platinum-based drugs. It involves measurements of creatinine clearance and other biochemical markers. Although nephrotoxicity can occur with the three Platinum-based drugs, it is most commonly associated with cisplatin treatment [31]. Acute kidney injury and hypomagnesemia due to the failure of the kidney to reabsorb magnesium affect up to $25 \%$ and $90 \%$ of cisplatin-treated patients, respectively. They are the two most common nephrotoxic adverse effects of cisplatin [32]. The risk of developing nephrotoxicity increases due to the presence of hypertension, pre-existing renal dysfunction, prior kidney removal, female gender, older age, and cigarette smoking [33]. Several medications like nonsteroidal anti-inflammatory drugs, aminoglycosides, cephalosporin antibiotics, ifosfamide, and methotrexate also increase patient risk when co-administrated with platinum compounds [32]. The mechanisms underlying cisplatin-induced nephrotoxicity are complicated, involving various stepwise processes. The most important one includes glutathione conjugate formation in the bloodstream (possibly mediated by glutathione-Stransferase), which would initiate metabolic activation of cisplatin inside the kidney, resulting in the production of more reactive toxic metabolites [33]. Glutathioneconjugates are cleaved into cysteinyl-glycine-conjugates when they move through the kidney by gamma-glutamyl trans-peptidase (GGT), which is found on the surface of the proximal tubule. Aminopeptidases expressed on the surface of the proximal tubule cells metabolize the cysteinyl-glycine-conjugates to cysteine-conjugates transferred to the proximal tubule cells. They undergo further biotransformation to yield highly reactive thiols by cysteine-S-conjugate beta-lyase [33]. These positively charged metabolites will then accumulate predominantly in the oppositely charged mitochondria. Therefore, both mitochondrial density and mitochondrial membrane potential appear to be associated with cisplatin cell susceptibility. Because the renal proximal tubule contains 
the highest number of mitochondria within the kidney, it is highly sensitive to cisplatin toxicity [33,34]. Several studies have proved that mitochondrial DNA or other mitochondrial targets can play a role in mediating cisplatininduced cell death rather than nuclear DNA damage [34].

\section{MYELOSUPPRESSION}

Myelosuppression describes a disorder in which the development of all blood cells in the bone marrow is disrupted, resulting in low levels of white and red blood cells, as well as platelets [35]. Although all platinum-based compounds cause hematological toxicity, carboplatininduced myelosuppression is the most common. Kidney function, age, and race are risk factors for hematological toxicities. It has been found that the severity of the side effects is directly related to the medication doses. Therefore, patients taking a platinum-based drug should be monitored for WBC, platelets, and absolute neutrophil counts (ANC) [35]. The occurrence of febrile neutropenia (fever with a temp. $>$ or $=38^{\circ} \mathrm{C}$ ) is of critical significance to patients, since $5-7 \%$ of those who experience this side effect die during hospitalization [36].

\section{OTOTOXICITY}

The most common ototoxicity for platinum-based drugs is persistent deafness in both ears. Hearing loss prevalence varies greatly, ranging from 4 to $90 \%$ depending on the medication dosage and the patient's age, with higher frequencies occurring with cisplatin [37]. Other side effects may include otalgia (ear pain), tinnitus, and vestibular alterations. Platinum-induced ototoxicity is caused by damage of the inner ear through a variety of mechanisms. One mechanism to consider is the induction of $\mathrm{p} 53$, cell cycle arrest, and apoptosis by the covalent binding of cisplatin with the guanine base of DNA. It results in the formation of inter and intrastrand chain cross-linking [38, 39]. Additionally, cisplatin produces ROS that induces lipid peroxidation and downregulates essential antioxidant enzymes such as glutathione reductase, glutathione peroxidase, catalase, and superoxide dismutase. It also increases apoptosis when accumulated in cochlear tissue [38]. Another possible ototoxicity mechanism is thought to be caused by the medication stimulating large conductance potassium channels, which causes follicle death [38]. Furthermore, the inflammatory pathway was linked to cisplatin-induced ototoxicity [40].

\section{CARDIOTOXICITY}

Compared to cisplatin, oxaliplatin and carboplatin have fewer clinical records of cardiotoxicity. Cisplatin produced the most prominent cardiotoxic side effect of tachycardia, which was the most prominent cardiotoxic side effect of cisplatin. It could appear minutes, hours, or even days after treatment, with the majority occurring silently and, in some cases, becoming fatal. Other cardiotoxic effects include symptomatic and asymptomatic arrhythmias, cardiac ischemia, diastolic disturbances, myocardial infarction, angina, pericarditis, thrombosis, and chronic heart failure [41]. While cardiotoxicity was not reported as a prominent side effect of platinum-based drugs. During the last ten years, there has been an increase in clinical studies documenting a broad range of cardiotoxic events during or shortly after cisplatin infusion [42]. Platinum-based medications, unlike some of the other chemotherapeutic medications, are not frequently prescribed with cardiac monitoring. It may contribute to underestimating their short and long-term cardiotoxic effects, especially when symptoms are silent [41]. Although the cause of cisplatininduced cardiotoxicity is unknown, it may occur due to poor magnesium reabsorption, or to its effect on the SA node [43]. Furthermore, there is some evidence that the cardiotoxicity of cisplatin is linked to a direct ROS attack on the heart [42]. The oxidative stress caused due to cisplatin is evidenced by the observed decrease in heart GSH levels, and an increase in MDA levels, as well as a decrease in oxidative enzyme activities. The resultant ROS can attack the membrane lipids of cardiac cells, resulting in lipid peroxidation with consequent reversible changes in membrane structures and functions, as well as cardiac enzyme leakage $[44,45]$.

\section{HEPATOTOXICITY}

The incidence of hepatotoxicity differs for each platinum compound. It has been found to range between $10 \%$ to $50 \%$ for oxaliplatin [46]. Both oxaliplatin and cisplatin are known for their ability to damage the liver sinusoids, resulting in sinusoidal dilation and obstruction, which subsequently leads to a decline in liver function and the development of symptoms like abdominal pain and swelling [47]. Sinusoidal damage could also result in nodular hyperplasia in the liver [48]. They cause hepatotoxicity by producing ROS in the mitochondria of sinusoidal epithelial cells. These ROS cause a rise in cytokine levels in the body, making healthy liver cells more susceptible to apoptosis and other forms of cell death [49]. Direct drug action on CYP450 enzymes, especially CYP2E1 and CYP4A11 enzymes, and the subsequent development of ROS, have also been linked to the level of hepatotoxicity in several studies [50].

\section{GASTROINTESTINAL TOXICITY}

Emetic symptoms such as nausea, vomiting, and dyspepsia are the most common gastrointestinal side effects of 
platinum drugs [51]. Many patients have insufficient food consumption, which can result in cachexia (weight loss), as well as some patients receiving platinum treatment can experience anorexia [52]. Cisplatin is a highly emetogenic medication with a high risk of nausea and vomiting in up to $90 \%$ of patients. Additionally, carboplatin and oxaliplatin are considered to be moderate-risk medications, with nausea and vomiting rates ranging from $30 \%$ to $90 \%$. After invading the GIT cells, platinum-based drugs released 5-HT, which is responsible for the majority of chemotherapy-induced peripheral neuropathy (CINV).When 5-HT is released, it binds to serotonin receptors, especially 5-HT3 receptors, in the peripheral and central nervous systems, causing CINV [53,54]. The mechanisms associated with the development of cachexia in patients treated with cisplatin are unknown; but, a decrease in the secretion of the appetite-stimulating hormone ghrelin has been suggested to play a role, according to results obtained from an animal study performed on fasted and cisplatin-treated rats [55]. Over the last six years, there have been significant advancements in novel platinum (II) and platinum (IV)-based complexes. They include ligands that act on specific cellular targets within cancer cells (for example, mitochondria) to ensure selectivity [56], overexpressed receptors such as integrin [57], biotin [58], estrogen [59], folate and epidermal growth factor receptors, proteins such as tubulin [60], and enzymes that aid in cancer cell growth [61].As a result, platinum compounds of this kind have shown important anticancer activity.

\section{Conclusion}

The platinum compounds cisplatin, carboplatin, and oxaliplatin, in particular, play an important role in oncology and have helped to improve the prognosis of patients with cancer. Although they are increasingly used worldwide, their effectiveness is related to the amount and nature of their side effects. That could lead to dose reductions and poor patient quality of life. A little research was done to investigate the causes that make some patients more vulnerable to platinum side effects. Based on these factors and due to the development of drug resistance, platinum-based chemotherapy has been restricted in the last decade. It has sparked a quest for new platinum-based drugs that differ from existing chemotherapeutics in terms of their mechanism of action. Newer platinum-based compounds solve some of these problems.

\section{ACKNOWLEDGMENT}

The authors thank the College of Pharmacy, University of Sulaimani for supporting the project.

\section{Conflicting Interest}

The authors declared no conflicts of interest.

\section{Data sharing statement}

N/A.

\section{REFERENCES}

1. Kelland L. The resurgence of platinum-based cancer chemotherapy. Nat Rev Cancer. 2007;7(8):573-584. doi: $10.1038 / \mathrm{nrc} 2167$.

2. Ferraro G, Massai L, Messori L, Merlino A. Cisplatin binding to human serum albumin: a structural study. Chem Commun (Camb). 2015;51(46):9436-9439. doi: 10.1039/c5cc01751c.

3. Park SB, Goldstein D, Krishnan AV, Lin CS, Friedlander ML, Cassidy J, et al. Chemotherapyinduced peripheral neurotoxicity: a critical analysis. $C A$ Cancer J Clin. 2013;63(6):419-437. doi: 10.3322/caac.21204.

4. Kalayda GV, Wagner $\mathrm{CH}$, Jaehde U. Relevance of copper transporter 1 for cisplatin resistance in human ovarian carcinoma cells. J Inorg Biochem. 2012;116:110. doi: 10.1016/j.jinorgbio.2012.07.010.

5. Johnstone TC, Suntharalingam K, Lippard SJ. The next generation of platinum drugs: Targeted $\mathrm{Pt}(\mathrm{II})$ agents, nanoparticle delivery, and $\mathrm{Pt}(\mathrm{IV})$ prodrugs. Chem Rev. 2016;116(5):3436-3486.

doi: 10.1021/acs.chemrev.5b00597.

6. Amable L. Cisplatin resistance and opportunities for precision medicine. Pharmacol Res. 2016;106:27-36. doi: 10.1016/j.phrs.2016.01.001.

7. Burridge N, Symons K, (eds.), Australian Injectable Drugs Handbook, (7th Ed.), 2017, Collingwood: Society of Hospital Pharmacists of Australia.

8. Kluetz PG, Chingos DT, Basch EM, Mitchell SA. Patient-reported outcomes in cancer clinical trials: Measuring symptomatic adverse events with the National Cancer Institute's patient-reported outcomes version of the common terminology criteria for adverse events (PRO-CTCAE). Am Soc Clin Oncol Educ Book. 2016;35:67-73. doi: 10.1200/EDBK_159514.

9. Park SB, Lin CS, Krishnan AV, Goldstein D, Friedlander ML, Kiernan MC. Oxaliplatin-induced neurotoxicity: changes in axonal excitability precede development of neuropathy. Brain. 2009;132(Pt 10):2712-2723. doi: 10.1093/brain/awp219. 
10. Kelley MR, Jiang Y, Guo C, Reed A, Meng H, Vasko MR. Role of the DNA base excision repair protein, APE1 in cisplatin, oxaliplatin, or carboplatin induced sensory neuropathy. PLoS One. 2014;9(9):e106485. doi: 10.1371/journal.pone.0106485.

11. Yan F, Liu JJ, Ip V, Jamieson SM, McKeage MJ. Role of platinum DNA damage-induced transcriptional inhibition in chemotherapy-induced neuronal atrophy and peripheral neurotoxicity. $J$ Neurochem. 2015;135(6):1099-1112. doi: 10.1111/jnc.13355.

12. Jimenez-Andrade JM, Herrera MB, Ghilardi JR, Vardanyan M, Melemedjian OK, Mantyh PW. Vascularization of the dorsal root ganglia and peripheral nerve of the mouse: implications for chemical-induced peripheral sensory neuropathies. Mol Pain. 2008;4:10. doi: 10.1186/1744-8069-4-10.

13. Sprowl JA, Ciarimboli G, Lancaster CS, Giovinazzo H, Gibson AA, Du G, et al. Oxaliplatin-induced neurotoxicity is dependent on the organic cation transporter OCT2. Proc Natl Acad Sci USA. 2013;110(27):11199-204. 10.1073/pnas.1305321110.

14. Ta LE, Espeset L, Podratz J, Windebank AJ. Neurotoxicity of oxaliplatin and cisplatin for dorsal root ganglion neurons correlates with platinum-DNA binding. Neurotoxicology. 2006;27(6):992-1002. doi: 10.1016/j.neuro.2006.04.010.

15. Gill JS, Windebank AJ. Cisplatin-induced apoptosis in rat dorsal root ganglion neurons is associated with attempted entry into the cell cycle. J Clin Invest. 1998;101(12):2842-2850. doi: 10.1172/JCI1130.

16. McDonald ES, Randon KR, Knight A, Windebank AJ. Cisplatin preferentially binds to DNA in dorsal root ganglion neurons in vitro and in vivo: a potential mechanism for neurotoxicity. Neurobiol Dis. 2005;18(2):305-313. doi: 10.1016/j.nbd.2004.09.013.

17. Podratz JL, Knight AM, Ta LE, Staff NP, Gass JM, Genelin K, et al. Cisplatin induced mitochondrial DNA damage in dorsal root ganglion neurons. Neurobiol Dis. 2011;41(3):661-668. doi: 10.1016/j.nbd.2010.11.017.

18. Bobylev I, Joshi AR, Barham M, Neiss WF, Lehmann HC. Depletion of mitofusin-2 causes mitochondrial damage in cisplatin-induced neuropathy. Mol Neurobiol. 2018;55(2):1227-1235. doi: $10.1007 / \mathrm{s} 12035-016-0364-7$.

19. Cullen KJ, Yang Z, Schumaker L, Guo Z. Mitochondria as a critical target of the chemotherapeutic agent cisplatin in head and neck cancer. $J$ Bioenerg Biomembr. 2007;39(1):43-50. doi: 10.1007/s10863006-9059-5.

20. Bruno PM, Liu Y, Park GY, Murai J, Koch CE, Eisen $\mathrm{TJ}$, et al. A subset of platinum-containing chemotherapeutic agents kills cells by inducing ribosome biogenesis stress. Nat Med. 2017;23(4):461471. doi: $10.1038 / \mathrm{nm} .4291$.

21. Marullo R, Werner E, Degtyareva N, Moore B, Altavilla G, Ramalingam SS, et al. Cisplatin induces a mitochondrial-ROS response that contributes to cytotoxicity depending on mitochondrial redox status and bioenergetic functions. PLoS One. 2013;8(11):e81162. doi: 10.1371/journal.pone.0081162.

22. Adelsberger H, Quasthoff S, Grosskreutz J, Lepier A, Eckel F, Lersch C. The chemotherapeutic oxaliplatin alters voltage-gated $\mathrm{Na}(+)$ channel kinetics on rat sensory neurons. Eur J Pharmacol. 2000;406(1):2532. doi: 10.1016/s0014-2999(00)00667-1.

23. Sittl R, Lampert A, Huth T, Schuy ET, Link AS, Fleckenstein J, et al. Anticancer drug oxaliplatin induces acute cooling-aggravated neuropathy via sodium channel subtype $\mathrm{Na}(\mathrm{V}) 1.6$-resurgent and persistent current. Proc Natl Acad Sci USA. 2012;109(17):6704-6709. doi: 10.1073/pnas.1118058109.

24. Sittl R, Carr RW, Fleckenstein J, Grafe P. Enhancement of axonal potassium conductance reduces nerve hyperexcitability in an in vitro model of oxaliplatininduced acute neuropathy. Neurotoxicology. 2010;31(6):694-700. doi: 10.1016/j.neuro.2010.07.006.

25. Leo M, Schmitt LI, Erkel M, Melnikova M, Thomale J, Hagenacker T. Cisplatin-induced neuropathic pain is mediated by upregulation of N-type voltage-gated calcium channels in dorsal root ganglion neurons. Exp Neurol. 2017;288:62-74. doi: 10.1016/j.expneurol.2016.11.003.

26. Di Cesare Mannelli L, Pacini A, Micheli L, Tani A, Zanardelli M, Ghelardini C. Glial role in oxaliplatininduced neuropathic pain. Exp Neurol. 2014;261:2233. doi: 10.1016/j.expneurol.2014.06.016.

27. Lees JG, Makker PG, Tonkin RS, Abdulla M, Park SB, Goldstein D, et al. Immune-mediated processes implicated in chemotherapy-induced peripheral neuropathy. Eur J Cancer. 2017;73:22-29. doi: 10.1016/j.ejca.2016.12.006. 
28. Carozzi VA, Canta A, Chiorazzi A. Chemotherapyinduced peripheral neuropathy: What do we know about mechanisms? Neurosci Lett. 2015;596:90-107. doi: 10.1016/j.neulet.2014.10.014.

29. Tsubaki M, Takeda T, Tani T, Shimaoka H, Suzuyama N, Sakamoto K, et al. PKC/MEK inhibitors suppress oxaliplatin-induced neuropathy and potentiate the antitumor effects. Int J Cancer. 2015;137(1):243-250. doi: 10.1002/ijc.29367.

30. Di Cesare Mannelli L, Pacini A, Matera C, Zanardelli M, Mello T, De Amici M, et al. Involvement of $\alpha 7$ nAChR subtype in rat oxaliplatin-induced neuropathy: effects of selective activation. Neuropharmacology. 2014;79:37-48. 10.1016/j.neuropharm.2013.10.034.

31. Tixier F, Ranchon F, Iltis A, Vantard N, Schwiertz V, Bachy E, et al. Comparative toxicities of 3 platinumcontaining chemotherapy regimens in relapsed/refractory lymphoma patients. Hematol Oncol. 2017;35(4):584-590. doi: 10.1002/hon.2328.

32. Launay-Vacher V, Rey JB, Isnard-Bagnis C, Deray G, Daouphars M; European Society of Clinical Pharmacy Special Interest Group on Cancer Care. Prevention of cisplatin nephrotoxicity: state of the art and recommendations from the European Society of Clinical Pharmacy Special Interest Group on Cancer Care. Cancer Chemother Pharmacol. 2008;61(6):903909. doi: 10.1007/s00280-008-0711-0.

33. Miller RP, Tadagavadi RK, Ramesh G, Reeves WB. Mechanisms of cisplatin nephrotoxicity. Toxins. 2010;2(11):2490-518. doi: 10.3390/toxins2112490.

34. Qian W, Nishikawa M, Haque AM, Hirose M, Mashimo M, Sato E, et al. Mitochondrial density determines the cellular sensitivity to cisplatin-induced cell death. Am J Physiol Cell Physiol. 2005;289(6):C1466-1475. doi: 10.1152/ajpcell.00265.2005.

35. Crawford J, Becker PS, Armitage JO, Blayney DW, Chavez J, Curtin P, et al. Myeloid growth factors, version 2.2017, NCCN clinical practice guidelines in oncology. J Natl Compr Canc Netw. 2017; 15(12):1520-1541. 10.6004/jnccn.2017.0175.

36. Laskey RA, Poniewierski MS, Lopez MA, Hanna RK, Secord AA, Gehrig PA, et al. Predictors of severe and febrile neutropenia during primary chemotherapy for ovarian cancer. Gynecol Oncol. 2012;125(3):625-630. doi: 10.1016/j.ygyno.2012.03.015.
37. Landier W. Ototoxicity and cancer therapy. Cancer. 2016;122(11):1647-1658. doi: 10.1002/cncr.29779.

38. Rybak LP, Mukherjea D, Jajoo S, Ramkumar V. Cisplatin ototoxicity and protection: clinical and experimental studies. Tohoku $J$ Exp Med. 2009;219(3):177-186. doi: 10.1620/tjem.219.177.

39. Cheng AG, Cunningham LL, Rubel EW. Mechanisms of hair cell death and protection. Curr Opin Otolaryngol Head Neck Surg. 2005;13(6):343-348. doi: 10.1097/01.moo.0000186799.45377.63.

40. Kim HJ, Oh GS, Lee JH, Lyu AR, Ji HM, Lee SH, et al. Cisplatin ototoxicity involves cytokines and STAT6 signaling network. Cell Res. 2011;21(6):944956. doi: 10.1038/cr.2011.27.

41. Raja W, Mir MH, Dar I, Banday MA, Ahmad I. Cisplatin induced paroxysmal supraventricular tachycardia. Indian $J$ Med Paediatr Oncol. 2013;34(4):330-332. doi: 10.4103/0971-5851.125262.

42. Patanè S. Cardiotoxicity: cisplatin and long-term cancer survivors. Int J Cardiol. 2014;175(1):201-2. doi: 10.1016/j.ijcard.2014.04.238.

43. Bashir H, Crom D, Metzger M, Mulcahey J, Jones D, Hudson MM. Cisplatin-induced hypomagnesemia and cardiac dysrhythmia. Pediatr Blood Cancer. 2007;49(6):867-869. doi: 10.1002/pbc.20804.

44. Ajith TA, Usha S, Nivitha V. Ascorbic acid and alphatocopherol protect anticancer drug cisplatin induced nephrotoxicity in mice: a comparative study. Clin Chim Acta. 2007;375(1-2):82-86. doi: 10.1016/j.cca.2006.06.011.

45. Yousef MI, Saad AA, El-Shennawy LK. Protective effect of grape seed proanthocyanidin extract against oxidative stress induced by cisplatin in rats. Food Chem Toxicol. 2009;47(6):1176-1183. doi: 10.1016/j.fct.2009.02.007.

46. Choti MA. Chemotherapy-associated hepatotoxicity: do we need to be concerned? Ann Surg Oncol. 2009;16(9):2391-2394. doi: 10.1245/s10434-0090512-7.

47. Nguyen-Khac E, Lobry C, Chatelain D, Fuks D, Joly JP, Brevet M, et al. A reappraisal of chemotherapyinduced liver injury in colorectal liver metastases before the Era of antiangiogenics. Int J Hepatol. 2013;2013:314868. doi: 10.1155/2013/314868.

48. Chun YS, Laurent A, Maru D, Vauthey JN. Management of chemotherapy-associated 
hepatotoxicity in colorectal liver metastases. Lancet Oncol. 2009;10(3):278-286. doi: 10.1016/S14702045(09)70064-6.

49. Waseem M, Bhardwaj M, Tabassum H, Raisuddin S, Parvez S. Cisplatin hepatotoxicity mediated by mitochondrial stress. Drug Chem Toxicol. 2015;38(4):452-459. doi: 10.3109/01480545.2014.992437.

50. Quintanilha JCF, de Sousa VM, Visacri MB, Amaral LS, Santos RMM, Zambrano T, et al. Involvement of cytochrome P450 in cisplatin treatment: implications for toxicity. Cancer Chemother Pharmacol. 2017;80(2):223-233. doi: 10.1007/s00280-017-3358$\mathrm{x}$.

51. Tamura K, Aiba K, Saeki T, Nakanishi Y, Kamura T, Baba H, et al. CINV Study Group of Japan. Breakthrough chemotherapy-induced nausea and vomiting: report of a nationwide survey by the CINV Study Group of Japan. Int $J$ Clin Oncol. 2017;22(2):405-412. doi: 10.1007/s10147-016-10697.

52. Crawford J. Cancer cachexia: Are we ready to take a step forward? Cancer. 2018;124(3):456-458. doi: 10.1002/cncr.31126.

53. Rapoport BL, Molasiotis A, Raftopoulos H, Roila F. Chemotherapy-induced nausea and vomiting. Biomed Res Int $\quad 2015 ; 2015: 457326 . \quad$ doi: $10.1155 / 2015 / 457326$.

54. Boussios S, Pentheroudakis G, Katsanos K, Pavlidis N. Systemic treatment-induced gastrointestinal toxicity: incidence, clinical presentation and management. Ann Gastroenterol. 2012;25(2):106-118. PMID: 24713845.

55. Yakabi K, Sadakane C, Noguchi M, Ohno S, Ro S, Chinen $\mathrm{K}$, et al. Reduced ghrelin secretion in the hypothalamus of rats due to cisplatin-induced anorexia. Endocrinology. 2010;151(8):3773-3782. doi: 10.1210/en.2010-0061.
56. Liu Z, Li Z, Du T, Chen Y, Wang Q, Li G, et al. Design, synthesis and biological evaluation of dihydro-2quinolone platinum(iv) hybrids as antitumor agents displaying mitochondria injury and DNA damage mechanism. Dalton Trans. 2021;50(1):362-375. doi: 10.1039/d0dt03194a.

57. Massaguer A, González-Cantó A, Escribano E, Barrabés S, Artigas $\mathrm{G}$, Moreno $\mathrm{V}$, et al. Integrintargeted delivery into cancer cells of a Pt(IV) pro-drug through conjugation to RGD-containing peptides. Dalton Trans. 2015;44(1):202-212. doi: 10.1039/c4dt02710h.

58. Zhao J, Hua W, Xu G, Gou S. Biotinylated platinum (IV) complexes designed to target cancer cells. J Inorg Biochem. 2017;176:175-180. doi: 10.1016/j.jinorgbio.2017.08.017.

59. Hu W, Zhao J, Hua W, Gou S. A study on platinum(iv) species containing an estrogen receptor modulator to reverse tamoxifen resistance of breast cancer. Metallomics. 2018;10(2):346-359. doi: $10.1039 / \mathrm{c} 7 \mathrm{mt} 00289 \mathrm{k}$.

60. Huang X, Huang R, Gou S, Wang Z, Liao Z, Wang H. Platinum(IV) complexes conjugated with phenstatin analog as inhibitors of microtubule polymerization and reverser of multidrug resistance. Bioorg Med Chem. 2017;25(17):4686-4700. doi: 10.1016/j.bmc.2017.07.011.

61. Kostrhunova H, Zajac J, Markova L, Brabec V, Kasparkova J. A Multi-action Pt IV conjugate with oleate and cinnamate ligands targets human epithelial growth factor receptor HER2 in aggressive breast cancer cells. Angew Chem Int Ed Engl. 2020;59(47):21157-21162. doi: 